\title{
RECENT DEVELOPMENTS IN LONG-TERM CARE POLICIES IN TURKEY
}

\author{
Dr. Emre Kol \\ Anadolu University, Faculty of Economic and Administrative Sciences, Eskişehir, \\ Turkey
}

\begin{abstract}
Long-term Care (LTC) policies continue to gain importance as the elderly population continues to increase in the world along with life expectancy. In this regard, this change in the population structure along with the transformation of the family structure make the LTC policies already being applied in Europen Union countries important for Turkey as well. In this study, LTC systems of EU countries will be taken into consideration with emphasis on issues for which Turkey can make use of the experiences of these countries. Care policies in Turkey will be handled and suggestions will be provided for the LTC insurance that is planned to be established. The convention numbered 102 of International Labor Organization (ILO) defines being destitute as a social risk as well along with health, disease, unemployment, old age and occupational diseases as part of the definition of basic social security rights. Thus, being destitute has been defined as a social problem in many developed countries and regulations that target the supporting of the individual in need of care along with his/her family have started to be included in social policies via various legal regulations. Germany was the first country to officially express being destitute and to include it in its social security system with the Social Care Insurance Law that went into effect in 1995.
\end{abstract}

Keywords: formal care; informal care; community-based care; social care insurance; public policy 